\title{
Biodegradable Polymers Induce CD54 on THP-1 Cells in Skin Sensitization Test
}

\author{
Yeon Suk Jung, ${ }^{1,2}$ Reiko Kato, ${ }^{1}$ and Toshie Tsuchiya ${ }^{1,3}$ \\ ${ }^{1}$ Division of Medical Devices, National Institute of Health Sciences, 1-18-1 Kamiyoga, Setagaya-ku, Tokyo 158-8501, Japan \\ ${ }^{2}$ Division of Urology, Cancer Institute of New Jersey, Robert Wood Johnson Medical School, New Brunswick, NJ 08901, USA \\ ${ }^{3}$ Medical Center for Translational Research, Osaka University Hospital, 2-15 Yamadaoka, Suita, Osaka 565-0871, Japan
}

Correspondence should be addressed to Toshie Tsuchiya, tsutoshi2005@gmail.com

Received 5 January 2011; Revised 18 May 2011; Accepted 8 June 2011

Academic Editor: Rosalind Labow

Copyright (c) 2011 Yeon Suk Jung et al. This is an open access article distributed under the Creative Commons Attribution License, which permits unrestricted use, distribution, and reproduction in any medium, provided the original work is properly cited.

Currently, nonanimal methods of skin sensitization testing for various chemicals, biodegradable polymers, and biomaterials are being developed in the hope of eliminating the use of animals. The human cell line activation test (h-CLAT) is a skin sensitization assessment that mimics the functions of dendritic cells (DCs). DCs are specialized antigen-presenting cells, and they interact with $\mathrm{T}$ cells and B cells to initiate immune responses. Phenotypic changes in DCs, such as the production of CD86 and CD54 and internalization of MHC class II molecules, have become focal points of the skin sensitization test. In this study, we used h-CLAT to assess the effects of biodegradable polymers. The results showed that several biodegradable polymers increased the expression of CD54, and the relative skin sensitizing abilities of biodegradable polymers were PLLG $(75: 25)<$ PLLC (40:60) < PLGA (50:50) $<$ PCG (50:50). These results may contribute to the creation of new guidelines for the use of biodegradable polymers in scaffolds or allergenic hazards.

\section{Introduction}

Until recently, studies of skin sensitization have used the guinea pig maximization test (GPMT) [1-3]. Currently, the local lymph node assay (LLNA) $[4,5]$ is often used as an alternative to GPMT. The advantages of LLNA are the ability to make dose-dependent evaluations, a decrease in animal usage, shorter experimental time periods, and lower costs $[6,7]$. In addition, a movement to prohibit the use of animals for safety testing of new materials is spreading throughout the world [8]. Recently, Ashikage et al. (2006) [9], Sakaguchi et al. (2006) [10] and several laboratories have reported the use of a new alternative to animal experiments, the human cell line activation test (h-CLAT) $[11,12]$.

Dendritic cells (DCs) are in contact with the skin and inner lining of the nose, lungs, stomach, and intestines [13]. They can also be found in an immature state in the blood. Antigens from viruses and microbes not only induce an adaptive immune response in DCs but also induce innate immunity to activate the immune system [14-16]. When skin sensitization develops, DCs immigrate to the secondary lymphoid organs to present naïve $\mathrm{T}$ cells [17]. Then, immature DCs mature and intercellular adhesion molecules, costimulatory molecules, and major histocompatibility complex II (MHC II) antigens (CD54, CD86, HLA-DR antigens) [18-21]. The immune reaction of DCs remains weak without costimulatory molecules. Therefore, skin sensitization in in vitro experiments is judged by expressions of CD54 and CD86.

THP-1 cells, a human monocyte cell line, are used in place of DCs in h-CLAT. We can evaluate phenotypical alterations on these THP- 1 cells. In the present studies, we assessed skin sensitization to biodegradable polymers by in vitro measures.

\section{Materials and Methods}

2.1. Cell Cultivation. THP-1 cells purchased from American Type Culture Collection (Manassas, Va, USA) were cultured with RPMI Medium 1640 (GIBCO, Grand Island, NY, USA) supplemented with $10 \%$ fetal bovine serum (FBS, Intergen, Purchase, NY, USA), $0.05 \mathrm{mM}$ 2-mercaptoethanol (GIBCO), 
TABLE 1: Condition and composition of biodegradable polymers.

\begin{tabular}{|c|c|c|c|c|}
\hline Sample & Biodegradable polymer & Composition & $\mathrm{Mn}^{*}$ & Catalyst \\
\hline P1 & Poly(L-lactide-glycolide copolymer)(PLLG) & $75: 25$ & 3540 & Without \\
\hline $\mathrm{P} 2$ & Poly(L-lactide-glycolide copolymer)(PLLG) & $75: 25$ & 3580 & $\mathrm{SnOct}_{2}$ \\
\hline P3 & Poly(x,L-lactide-glycolide copolymer)(PLGA) & $50: 50$ & 3550 & Without \\
\hline $\mathrm{P} 4$ & Poly $(\mathrm{L}$-lactide)(PLLA) & 100 & 3390 & Without \\
\hline P5 & Poly(L-lactide-caprolactone copolymer)(PLLC) & $40: 60$ & 3110 & Without \\
\hline P6 & Poly(caprolactone glycolide copolymer)(PCG) & $50: 50$ & 3000 & Without \\
\hline
\end{tabular}

${ }^{*}$ number average molecular weight $(\mathrm{Mn})$.

and $1 \%$ streptomycin (GIBCO). The cells used in testing were between 2 weeks to 2 months old.

2.2. Biodegradable Polymers and Their Treatment. Biodegradable polymers P1 to P6 (Table 1) were obtained from Taki Chemical Co., Ltd. (Hyogo, Japan). We made 6 initial stock solutions by dissolving the biodegradable polymers in dimethyl sulfoxide (DMSO, Sigma, Ayrshire, UK). The biodegradable polymers P1, P2, P3, P4, P5, and P6 were dissolved separately in DMSO. 2,4Dinitrochlorobenzene (DNCB, Sigma-Aldrich, St. Louis, Mo, USA) was also dissolved in DMSO and used as a positive control for the skin sensitization test. We made 6 substock solutions of each polymer using two-times dilution series. These sub-stock solutions were diluted 20 times with RPMI medium 1640. Finally, the working solutions were added to the cells at 100 times dilution.

2.3. Analysis by Flow Cytometry. Cells were seeded on 96well plate (Corning, Corning, NY, USA) at a density of $1.6 \times 10^{5}$ (cells/160 $\mu \mathrm{L} /$ well) with the working solutions and cultivated in a $\mathrm{CO}_{2}$ incubator for $24 \mathrm{~h}$. The cultivated cells were moved to V-shaped culture plates (BMbio, Tokyo, Japan), and then the cells were collected by centrifuging at $700 \times \mathrm{g}$ for $3 \mathrm{~min}$. The cells were washed 3 times using FACS buffer (PBS+0.1\% BSA). They were blocked with $200 \mu \mathrm{L}$ of 0.01\% Globulins Cohn fraction II and III (Sigma-Aldrich, St. Louis, MO, USA) for $15 \mathrm{~min}$ on ice. The supernatants were removed from the plate after centrifuging. Fluorescein isothiocyanate (FITC)-conjugated mouse antihuman CD86 antibody (CD86, BD Pharmingen, San Jose, CA, USA), monoclonal mouse anti-human CD54, ICAM-1/FITC antibody, (CD54, Dako, Denmark), or mouse IgG1/FITC antibody (IgG, Dako) was added to the plates, and the plates were shaded from the light for $30 \mathrm{~min}$. The plates were washed 3 times with FACS buffer. Finally, the cells were resuspended in $400 \mu \mathrm{L}$ FACS buffer and subjected to flow cytometry on a BD FACSCalibur cell sorter (Becton Dickinson Co., Ltd., Franklin Lakes, NJ, USA) to analyze the surface of the cells for CD markers.

2.4. Propidium Iodide Assay of Cell Viability. During flow cytometry analysis, propidium iodide (PI, $0.625 \mu \mathrm{g} / \mathrm{mL}$ ) was added to the suspended cells to measure the number of living cells. Each test was done in triplicate, and 10,000 living cells were counted each time by the BD FACSCalibur flow cytometer.

2.5. Relative Fluorescence Intensity. We separated the living cells from the PI-dyed dead cells using the Flowjo computer program. We evaluated the skin sensitization caused by the biodegradable polymers by measuring the fluorescence intensity of CD86, CD54, and IgG. At less than 50\% cell viability, there is a possibility of cell wall damage and irregular binding of antibodies. Therefore, we measured cell viability by calculating the relative fluorescence intensity (RFI) as shown below by the expression levels of CD86 and CD54.

$$
\operatorname{RFI}(\%)=\frac{\text { MFI of cells with polymer }- \text { MFI of isotype control cells with polymer }}{\text { MFI of vehicle control cells }- \text { MFI of vehicle isotype control cells }} \times 100
$$

*MFI: (geometric) mean of fluorescence intensity.

\section{Results}

3.1. Cell Viability by PI Assay. DNCB, a positive control, was used to test cell viability and expression levels of the CD markers on THP-1 cells. DNCB at $5.2 \mu \mathrm{g} / \mathrm{mL}$ produced high RFI expression levels, while the changes in cell viability were miniscule. At the same time, we tested the effect of the DMSO solvent on cell viability over time (Figure 1). The cell viabilities did not change during the 24-hour incubation with DNCB and DMSO. These results show that a 24hours incubation and $5.2 \mu \mathrm{g} / \mathrm{mL}$ DNCB were an appropriate incubation time and concentration for the skin sensitization test.

Next we tested the effects of biodegradable polymers on the viabilities of THP-1 cells. The cells were incubated for 24 hours with various concentrations of the biodegradable polymers and subjected to PI assay (Figure 2). The results show 


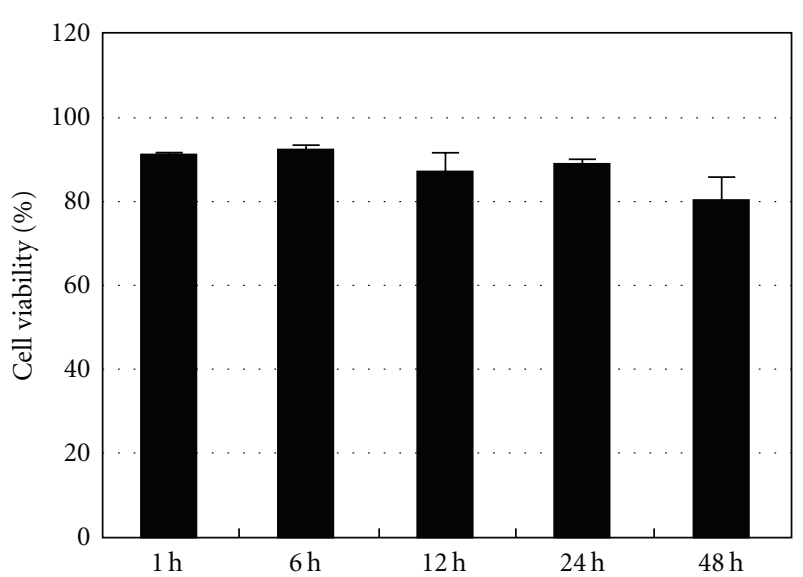

(a)

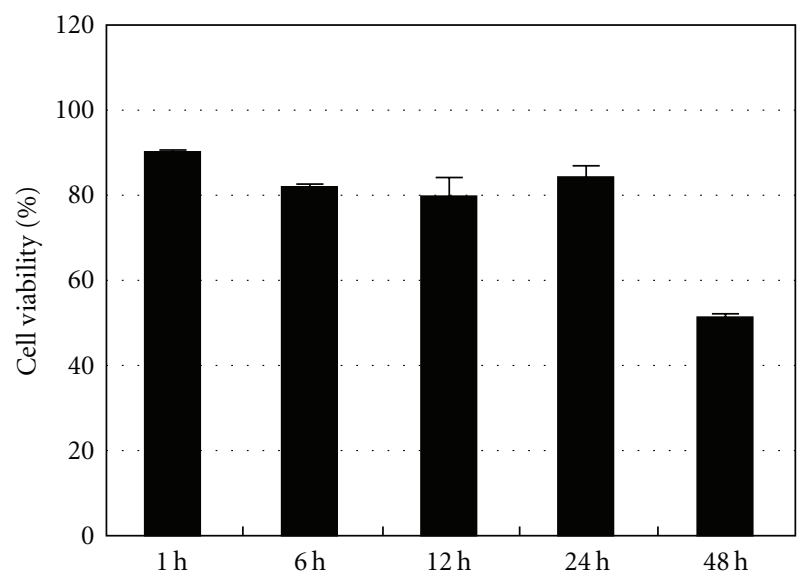

(c)

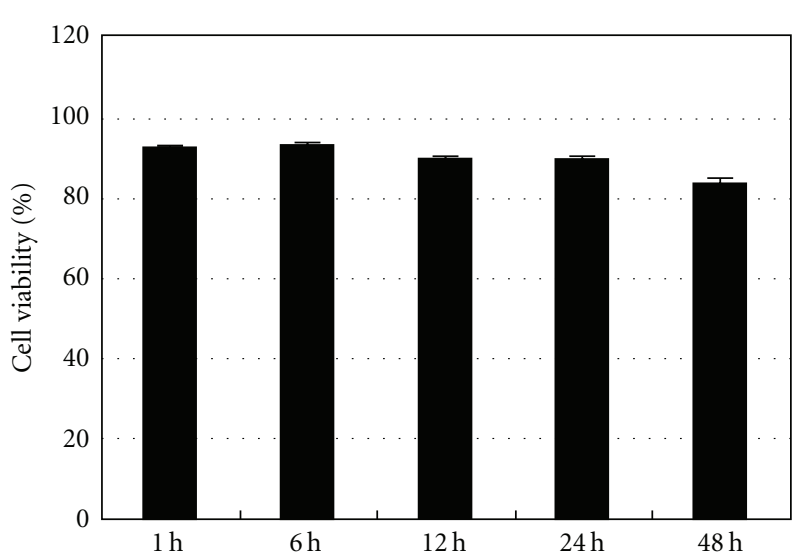

(b)

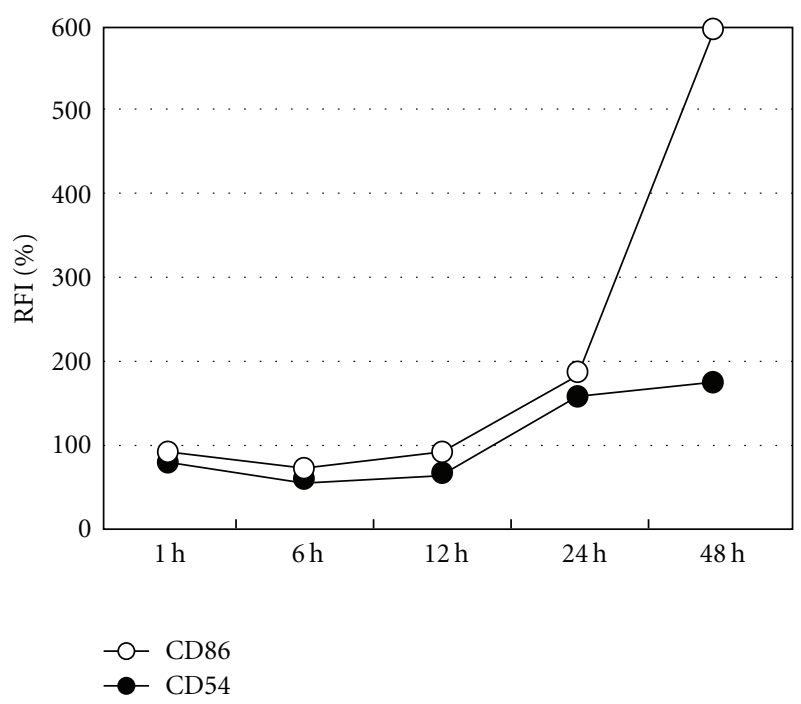

(d)

FIGURE 1: Comparison between cell viabilities of positive control, solvent, and medium only. All cell viabilities were measured by time progression. (a) Cell viability in RPMI medium 1640, (b) cell viability in DMSO ( $2 \mu \mathrm{L} / \mathrm{mL}$ ), (c) cell viability in DNCB (5.2 $\mu \mathrm{g} / \mathrm{mL}$ ), and (d) CD54 and CD86 expression levels over time with DNCB $(5.2 \mu \mathrm{g} / \mathrm{mL})$.

that cell viabilities differed depending on the biodegradable polymer. However, the tendencies of decreasing cell viabilities were proportional to the concentrations of the polymers. Sample P6 was not tested because it did not dissolve at $2 \mathrm{mg} / \mathrm{mL}$.

\subsection{Expression of CD54 and CD86 Markers (Alternative RFI).} After 24-hour incubation, variations of the RFI as an index of skin sensitization were determined by measuring the fluorescence intensity of CD86 and CD54 immune markers. The CD54 RFI increased dose dependently with increased concentration of all polymers (Figure 3 ). In contrast, the CD86 RFI decreased in all of the polymer solutions. These results showed that as the concentrations of degradable polymers were augmented, only the CD54 marker was expressed. P1, P3, P5, and P6 produced high skin sensitization as shown by the RFI reaching 200. In particular, P6 showed an RFI over 200 at $250 \mu \mathrm{g} / \mathrm{mL}$.
3.3. Estimated Concentration of CD54 in Biodegradable Polymers. From the RFI experiments (Figure 3), we know that some of the biodegradable polymers cause expression of only CD54 costimulatory molecules on the dendritic cells. Based on previous studies, the effective concentrations (EC) 200 (CD54) and EC150 (CD86) became the standard for judging skin sensitization in cases of CD54. P1, P3, P5, and P6 were estimated to cause skin sensitization by this method, at the concentrations of polymers shown in Table 2.

\section{Discussion}

Since the role of DCs in skin sensitization has been known, research using human peripheral blood has expanded, but its use has limits due to the limited number of DCs in the blood $[22,23]$. The expression levels of the markers CD54 and CD86 have been shown to be closely related to how sensitive skin is $[24,25]$. Previous studies have set RFI value criteria for 


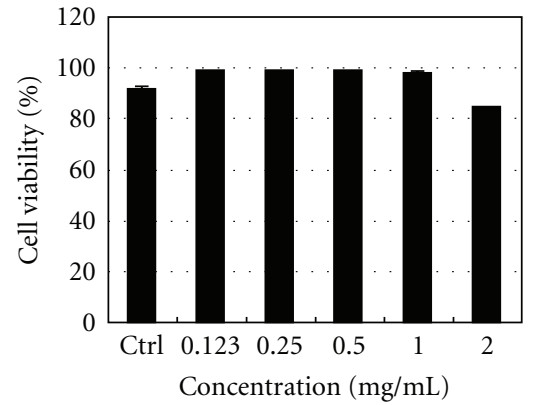

(a)

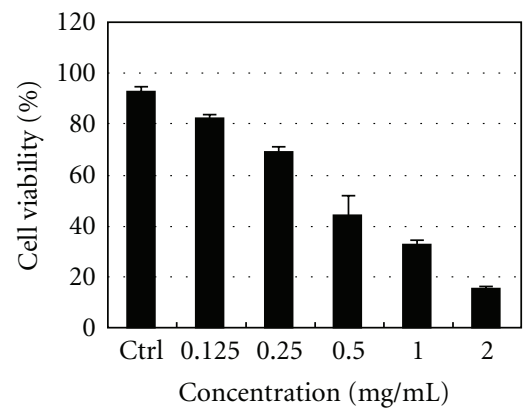

(d)

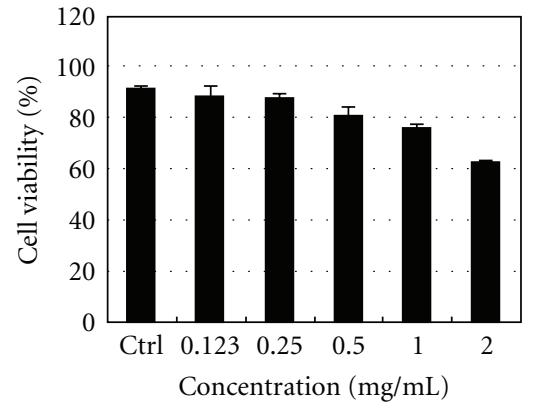

(b)

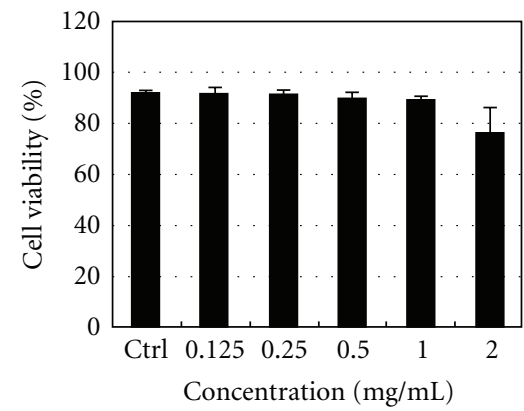

(e)

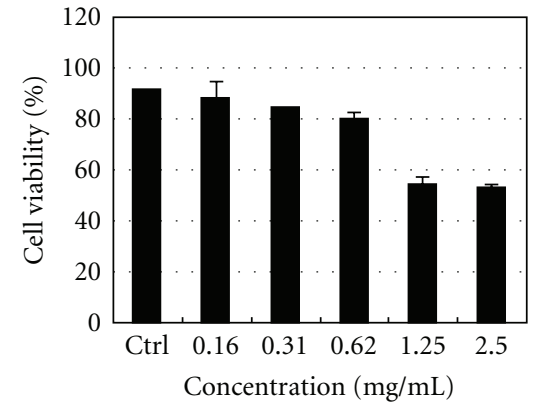

(c)

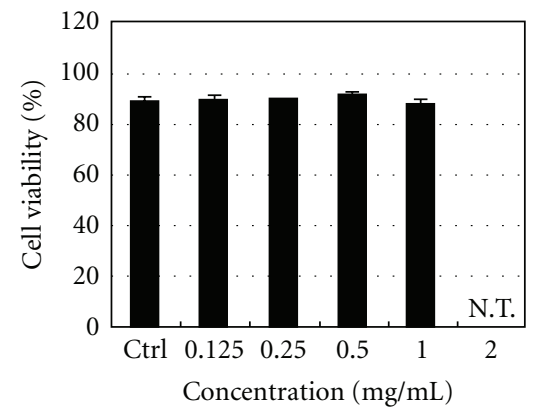

(f)

Figure 2: Effects of biodegradable polymers on cell viability by concentration. THP-1 cells were incubated with dissolved biodegradable polymers for 24 hours. Using flow cytometry with PI $(0.625 \mu \mathrm{g} / \mathrm{mL}$ ), only living cells were counted in total cells. (a) P1, (b) P2, (c) P3, (d) P4, (e) P5, and (f) P6, N.T.: not tested.

TABLE 2: Effects of EC 200 on biodegradable polymers.

\begin{tabular}{lccccc}
\hline Sample & $\begin{array}{c}\text { Low } \\
\text { FRI }\end{array}$ & $\begin{array}{c}\text { Low } \\
\text { conc. } \\
\mathrm{b}\end{array}$ & $\begin{array}{c}\text { High } \\
\text { RFI }\end{array}$ & $\begin{array}{c}\text { High } \\
\text { conc. } \\
\mathrm{c}\end{array}$ & EC $(\mathrm{mg} / \mathrm{mL})$ \\
\hline P1 & 174.00 & 1.00 & 265.00 & 2.00 & 1.29 \\
P3 & 178.00 & 0.62 & 250.00 & 1.25 & 0.81 \\
P5 & 104.00 & 0.50 & 212.00 & 1.00 & 0.94 \\
P6 & 108.00 & 0.13 & 236.00 & 0.25 & 0.21 \\
\hline
\end{tabular}

Formula: EC200 $=(d-b) /(c-a) \times(200-a)+b$.

CD86 ( $\geq 150 \%)$ and CD54 ( $\geq 200 \%)[26,27]$. In this study, we used h-CLAT as the in vitro skin sensitization method and investigated whether biodegradable polymers sensitize skin by using these markers in vitro. The expression levels of these markers on cells were first counted by geometric means of flow cytometry, and then the RFI values were calculated by the RFI formula. Polymers that stimulated CD86 at 150\% or more and CD54 at 200\% or more were judged to be sensitizers as in previous studies.

Initially, we tested the effects of DNCB and DMSO on cell viability over time. When the cell viability of the medium concentration group was assumed to be $100 \%$, the cell viability of the DMSO group showed only minuscule change. After 48 hours, the cell viability of both the DMSO group and the medium concentration group had decreased only slightly. The results showed that the cell viability was not changed by the solvent DMSO (Figure 1). Further, the addition of
$5.2 \mu \mathrm{g} / \mathrm{mL}$ of DNCB to the cells did not result in a large change in cell viability up to 24 hours. At 48 hours, however, the cell viability had decreased to less than $60 \%$. Therefore, using DNCB as the positive control for skin sensitization was most appropriate when the marker was measured after 24 hours.

We cultured all samples with biodegradable polymers and measured the cell viability and expression levels of CD54 and CD86 at 24 hours. Each polymer exerted a different effect on cell viability (Figure 2). We found that polymer P4 sharply decreased the cell viability as the dosage was increased; therefore, it was possibly the most toxic biodegradable polymer. The polymers $\mathrm{P} 1$ and $\mathrm{P} 5$ at the highest concentration showed cell viabilities of $70 \%$ or more. Therefore, their effect on cell viability is considered weak.

The polymers increased the expression of the CD54 marker but did not increase the expression of the CD86 marker (Figure 3). The P1, P3, P5, and P6 polymers stimulated high expression levels of the CD54 marker. P1 and P5 stimulated high expression levels of the CD54 marker while not affecting cell viability. P4 produced the lowest expression of the CD54 marker and the lowest cell viability of all the polymers. These results suggest that the biodegradable polymers affect only the CD54 marker and differ in their composition.

During the past several decades, biodegradable polymers have been used in clinical medicine, and they have been reported to have minimal to more substantial side effects $[28,29]$. Generally, it is known that there are delayed antigenantibody reactions due to partial wear-out and inflammation 


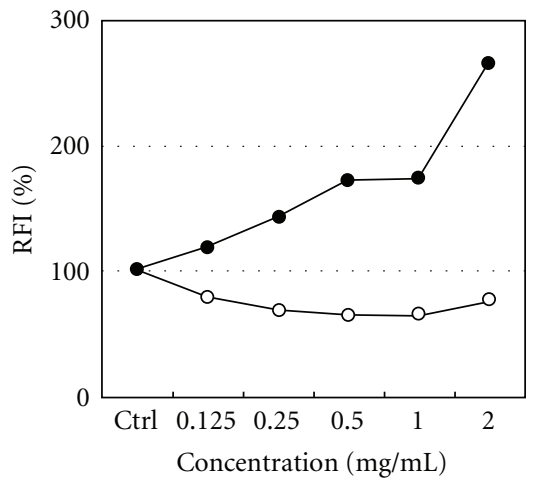

(a)

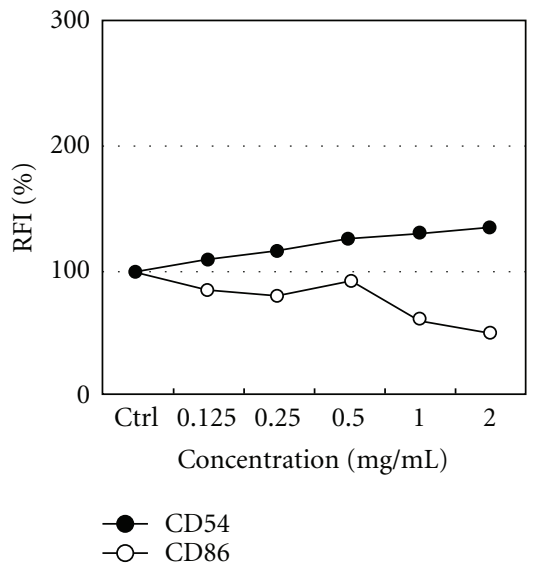

(d)

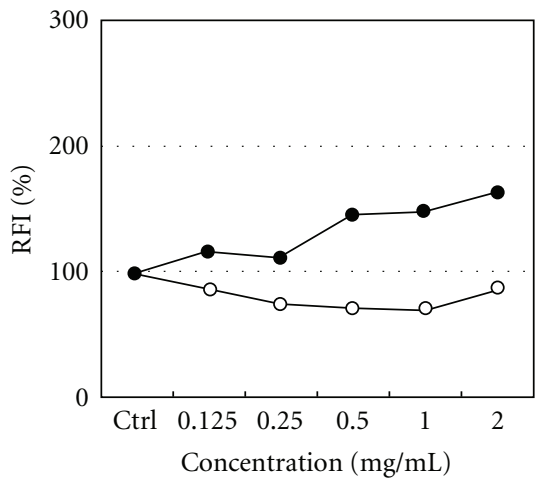

(b)

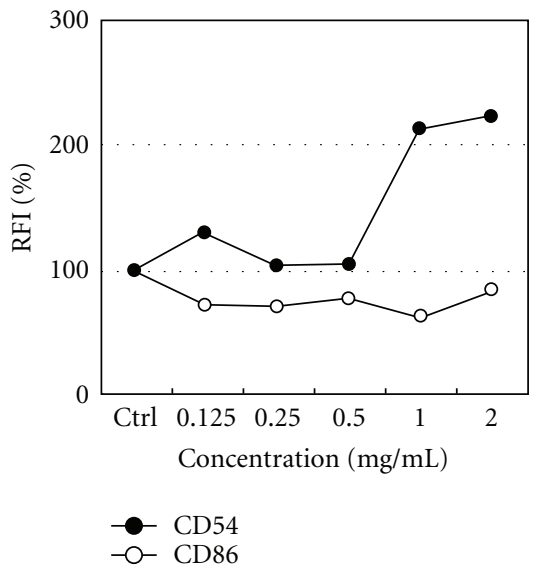

(e)

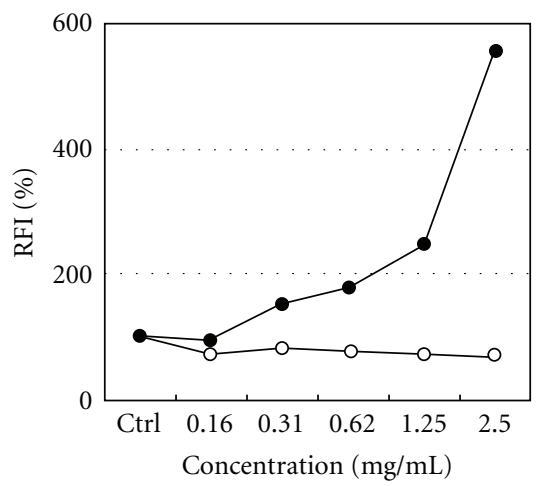

(c)

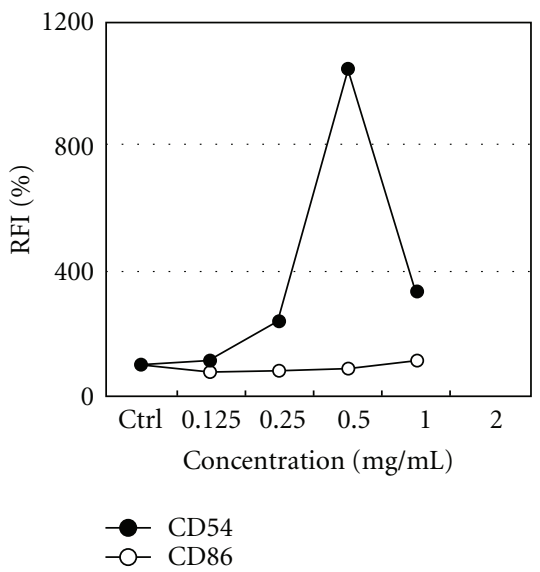

(f)

FIGURE 3: RFI results for each biodegradable polymers. Only living cells were selected by using PI dye. Next, we displayed living cells as FITC histograms, and then we showed the power of the Geom mean. RFI (\%) was calculated from Geom mean as described in test. (a) P1, (b) P2, (c) P3, (d) P4, (e) P5, and (f) P6, N.T.: not tested.

due to long usage of a biomedical material. This research may suggest that there is a relationship between CD54 and delayed antigen-antibody reactions. It is thought to be necessary to compare the results of the effects of biodegradable polymers on dendritic cells with those of local lymph node assays (LLNA).

\section{Conclusion}

Until now, biodegradable polymers have been little studied as causes of in vitro sensitization. We tested biodegradable polymers by h-CLAT. We could not assess P4 because even a low concentration of P4 caused cell death. Further, skin sensitization was not increased by P2. Biodegradable polymers that showed evidence of causing skin sensitization expressed as only CD54 were PLLG $(75: 25)<$ PLLC $(40: 60)$ $<$ PLGA $(50: 50)<$ PCG $(50: 50)$. We determined that the different compositions of biodegradable polymers produced clearly different effects on skin sensitization. In conclusion, skin sensitization due to exposure to the biodegradable polymers can be examined without animal experiments.

\section{Acknowledgments}

Our heartfelt appreciation goes to Dr. Nukada Yuko, Dr. Abo Takayuki, Dr. Ito Yuichi, Dr. Nishiyama, and Dr. Kawai Shuji from Kao Corporation (Tochiki, Japan) for their valuable suggestions. We are also indebted to Mr. Okada and Mr. M. Terao from TAKI CHEMICAL CO., LTD., whose preparations of substances made enormous contribution to our work. Finally, I would like to thank MHLW for a grant that made it possible to complete this study.

\section{References}

[1] T. Maurer, "Guinea pigs in hypersensitivity testing," Methods, vol. 41, no. 1, pp. 48-53, 2007.

[2] I. Kimber, D. A. Basketter, K. Berthold et al., "Skin sensitization testing in potency and risk assessment," Toxicological Sciences, vol. 59, no. 2, pp. 198-208, 2001.

[3] R. Kreiling, H. M. Hollnaqel, L. Hareng et al., "Comparison of the skin sensitizing potential of unsaturated compounds as assessed by the murine local node assay (LLNA) and the guinea pig maximization test (GPMT)," Food and Chemical Toxicology, vol. 46, no. 6, pp. 1896-1904, 2008. 
[4] I. Kimber, R. J. Dearman, E. W. Scholes, and D. A. Basketter, "The local lymph node assay: developments and applications," Toxicology, vol. 93, no. 1, pp. 13-31, 1994.

[5] G. F. Gerberick, C. A. Ryan, R. J. Dearman, and I. Kimber, "Local lymph node assay (LLNA) for detection of sensitization capacity of chemicals," Methods, vol. 41, no. 1, pp. 54-60, 2007.

[6] R. J. Dearman, D. A. Basketter, and I. Kimber, "Local lymph node assay: use in hazard and risk assessment," Journal of Applied Toxicology, vol. 19, no. 5, pp. 299-306, 1999.

[7] M. Takeyoshi, K. Iida, K. Shiraishi, and S. Hoshuyama, "Novel approach for classifying chemicals according to skin sensitizing potency by non-radioisotopic modification of the local lymph node assay," Journal of Applied Toxicology, vol. 25, no. 2, pp. 129-134, 2005.

[8] Y. Ohno, "Importance of research on alternatives to animal experiments in pharmaceutical sciences," Yakugaku Zasshi, vol. 128, no. 5, pp. 735-740, 2008.

[9] T. Ashikaga, Y. Yoshida, M. Hirota et al., "Development of an in vitro skin sensitization test using human cell lines: the human cell line activation test (h-CLAT). I. Optimization of the h-CLAT protocol," Toxicology in Vitro, vol. 20, no. 5, pp. 767-773, 2006.

[10] H. Sakaguchi, T. Ashikaga, M. Miyazawa et al., "Development of an in vitro skin sensitization test using human cell lines; human Cell Line Activation Test (h-CLAT) II. An interlaboratory study of the h-CLAT,' Toxicology in Vitro, vol. 20, no. 5, pp. 774-784, 2006.

[11] U. Neisius, P. Brand, S. Plochmann, J. Saloga, J. Knop, and D. Becker, "Detection of increased tyrosine phosphorylation in murine Langerhans cells after stimulation with contact sensitizers," Archives of Dermatological Research, vol. 291, no. 1, pp. 22-27, 1999.

[12] B. C. Hulette, C. A. Ryan, and G. F. Gerberick, "Elucidating changes in surface marker expression of dendritic cells following chemical allergen treatment," Toxicology and Applied Pharmacology, vol. 182, no. 3, pp. 226-233, 2002.

[13] T. Ashikaga, H. Sakaguchi, K. Okamoto et al., "Assessment of the human Cell Line Activation Test (h-CLAT) for Skin Sensitization; Results of the First Japanese Inter-laboratory Study," Alternatives to Animal Testing, vol. 13, no. 1, pp. 2735, 2008.

[14] E. S. Trombetta and I. Mellman, "Cell biology of antigen processing in vitro and in vivo," Annual Review of Immunology, vol. 23, pp. 975-1028, 2005.

[15] M. Brandes, K. Willimann, and B. Moser, "Immunology: professional antigen-presentation function by human $\gamma \delta$ cells," Science, vol. 309, no. 5732, pp. 264-268, 2005.

[16] C. Moulon, J. Peguet-Navarro, P. Courtellemont, G. Redziniak, and D. Schmitt, "In vitro primary sensitization and restimulation of hapten-specific T cells by fresh and cultured human epidermal Langerhans' cells," Immunology, vol. 80, no. 3, pp. 373-379, 1993.

[17] P. Hamrah and M. R. Dana, "Corneal antigen-presenting cells," Chemical Immunology and Allergy, vol. 92, pp. 58-70, 2007.

[18] V. Vidal, J. Dewulf, and G. M. Bahr, "Enhanced maturation and functional capacity of monocyte-derived immature dendritic cells by the synthetic immunomodulator Murabutide," Immunology, vol. 103, no. 4, pp. 479-487, 2001.

[19] S. Aiba, A. Terunuma, H. Manome, and H. Tagami, "Dendritic cells differently respond to haptens and irritants by their production of cytokines and expression of co-stimulatory molecules," European Journal of Immunology, vol. 27, no. 11, pp. 3031-3038, 1997.
[20] K. D. Coutant, A. B. D. De Fraissinette, A. Cordier, and P. Ulrich, "Modulation of the activity of human monocytederived dendritic cells by chemical haptens, a metal allergen, and a staphylococcal superantigen," Toxicological Sciences, vol. 52, no. 2, pp. 189-198, 1999.

[21] M. S. Muthu and S. Singh, "Studies on biodegradable polymeric nanoparticles of risperidone: in vitro and in vivo evaluation," Nanomedicine, vol. 3, no. 3, pp. 305-319, 2008.

[22] K. Liu, C. Waskow, X. Liu, K. Yao, J. Hoh, and M. Nussenzweig, "Origin of dendritic cells in peripheral lymphoid organs of mice," Nature Immunology, vol. 8, no. 6, pp. 578-583, 2007.

[23] P. Hubert, L. Bousarqhin, R. Greimers, E. Rranzen-Detrooz, J. Boniver, and P. Delvenne, "Production of large numbers of Langerhans' cells with intraepithelial migration ability in vitro," Experimental Dermatology, vol. 14, no. 6, pp. 469-477, 2005.

[24] C. Moulon, J. Peguet-Navarro, P. Courtellemont, G. Redziniak, and D. Schmitt, "In vitro primary sensitization and restimulation of hapten-specific $\mathrm{T}$ cells by fresh and cultured human epidermal Langerhans' cells," Immunology, vol. 80, no. 3, pp. 373-379, 1993.

[25] H. Rizova, P. Carayon, A. Barbier, F. Lacheretz, L. Dubertret, and L. Michel, "Contact allergens, but not irritants, alter receptor-mediated endocytosis by human epidermal Langerhans cells," British Journal of Dermatology, vol. 140, no. 2, pp. 200-209, 1999.

[26] T. Ashikaga, M. Hoya, H. Itagaki, Y. Katsumura, and S. Aiba, "Evaluation of CD86 expression and MHC class II molecule internalization in THP-1 human monocyte cells as predictive endpoints for contact sensitizers," Toxicology in Vitro, vol. 16, no. 6, pp. 711-716, 2002.

[27] Y. Yoshida, H. Sakaguchi, Y. Ito, M. Okuda, and H. Suzuki, "Evaluation of the skin sensitization potential of chemicals using expression of co-stimulatory molecules, CD54 and CD86, on the naive THP-1 cell line," Toxicology in Vitro, vol. 17, no. 2, pp. 221-228, 2003.

[28] K. Greish, "Enhanced permeability and retention of macromolecular drugs in solid tumors: a royal gate for targeted anticancer nanomedicines," Journal of Drug Targeting, vol. 15, no. 7-8, pp. 457-464, 2007.

[29] S. D. Bruck and E. P. Mueller, "Materials and biological aspects of synthetic polymer in controlled drug release systems: problems and challenges," Critical Reviews in Therapeutic Drug Carrier Systems, vol. 5, no. 3, pp. 171-187, 1988. 

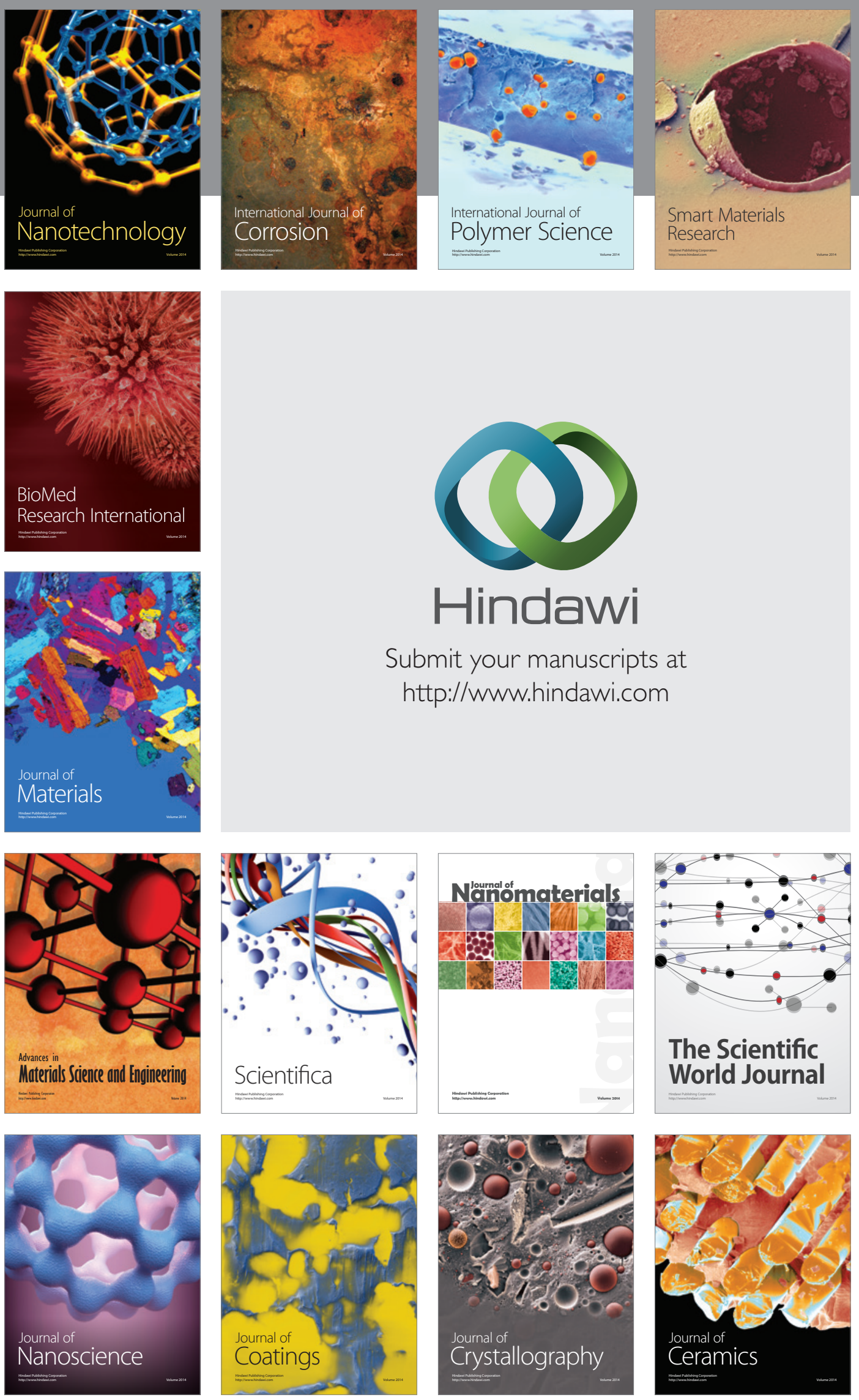

The Scientific World Journal

Submit your manuscripts at

http://www.hindawi.com

\section{World Journal}

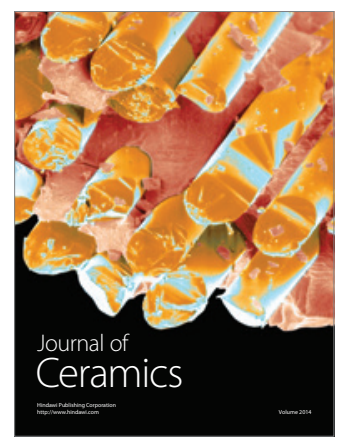

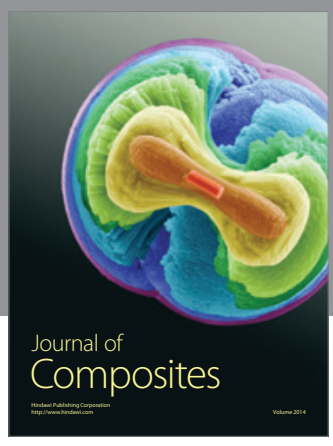
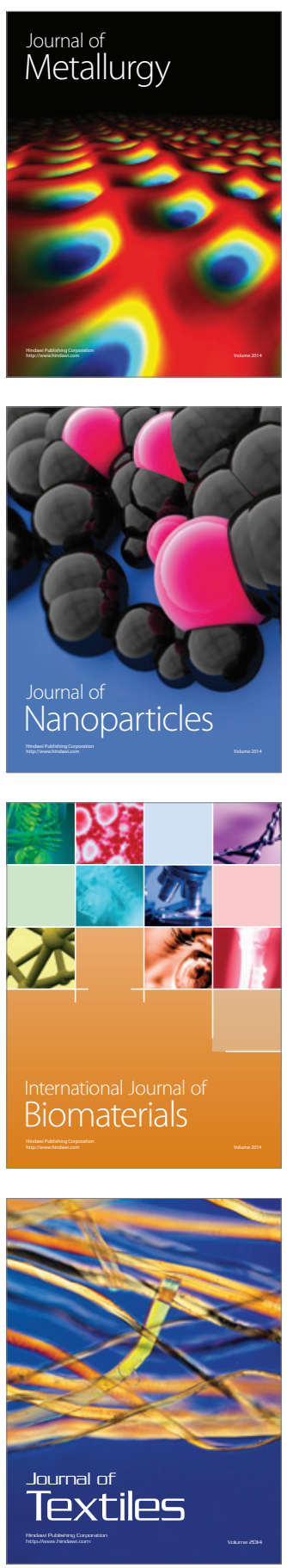